\title{
Identification of Fatty Acid Desaturase 6 in Golden Pompano Trachinotus Ovatus (Linnaeus 1758) and Its Regulation by the PPAR $\alpha$ b Transcription Factor
}

\author{
Ke-Cheng Zhu ${ }^{1,2,3} \mathbb{C}_{\text {, Ling Song }}{ }^{1}$, Hua-Yang Guo ${ }^{1,2}$, Liang Guo ${ }^{1,2,3}$, Nan Zhang ${ }^{1,2,3}$, \\ Bao-Suo Liu ${ }^{1,2,3}$, Shi-Gui Jiang ${ }^{1,2,4}$ and Dian-Chang Zhang ${ }^{1,2,3, *}$ \\ 1 Key Laboratory of South China Sea Fishery Resources Exploitation and Utilization, Ministry of Agriculture \\ and Rural Affairs, South China Sea Fisheries Research Institute, Chinese Academy of Fishery Sciences, \\ 231 Xingang Road West, Haizhu District, Guangzhou 510300, China; zkc537@163.com (K.-C.Z.); \\ 18620160853@163.com (L.S.); guohuayang198768@163.com (H.-Y.G.); zsdxgl@163.com (L.G.); \\ 398730316@163.com (N.Z.); liubaosuo343@163.com (B.-S.L.); jiangsg@21cn.com (S.-G.J.) \\ 2 Engineer Technology Research Center of Marine Biological Seed of Guangdong Province, \\ Guangzhou 510300, China \\ 3 Key Laboratory of Fishery Ecology \& Environment, South China Sea Fisheries Research Institute, \\ Guangzhou 510300, China \\ 4 South China Sea Bio-Resource Exploitation and Utilization Collaborative Innovation-Center, \\ South China Sea Fisheries Research Institute, Guangzhou 510300, China \\ * Correspondence: zhangdch@scsfri.ac.cn; Tel.: +86-02089108316; Fax: +86-02089022702
}

Received: 5 November 2018; Accepted: 18 December 2018; Published: 21 December 2018

\begin{abstract}
Fatty acid desaturases are rate-limiting enzymes in long-chain polyunsaturated fatty acid biosynthesis. The transcription factor peroxisome proliferator-activated receptor alpha $b$ (PPAR $\alpha b)$ regulates lipid metabolism in mammals, however, the mechanism whereby PPAR $\alpha \mathrm{b}$ regulates fatty acid desaturases is largely unknown in fish. In this study, we report the full length cDNA sequence of Trachinotus ovatus fatty acid desaturase, which encodes a 380 amino acid polypeptide, possessing three characteristic histidine domains. Phylogenetic and gene exon/intron structure analyses showed typical phylogeny: the T. ovatus fatty acid desaturase contained a highly conserved exon/intron architecture. Moreover, functional characterization by heterologous expression in yeast indicated that T. ovatus desaturase was a fatty acid desaturase, with $\Delta 4 / \Delta 5 / \Delta 8$ Fad activity. Promoter activity assays indicated that ToFads 6 desaturase transcription was positively regulated by PPAR $\alpha$ b. Similarly, PPAR $\alpha \mathrm{b}$ RNA interference decreased ToPPAR $\alpha \mathrm{b}$ and ToFads6 expression at the mRNA and protein levels in a time-dependent manner. Mutation analyses showed that the M2 binding site of PPAR $\alpha \mathrm{b}$ was functionally important for protein binding, and transcriptional activity of the ToFads6 promoter was significantly decreased after targeted mutation of M2. Electrophoretic mobile shift assays confirmed that PPAR $\alpha \mathrm{b}$ interacted with the binding site of the ToFads 6 promoter region, to regulate ToFads 6 transcription. In summary, PPAR $\alpha$ b played a vital role in ToFads 6 regulation and may promote the biosynthesis of long-chain polyunsaturated fatty acids by regulating ToFads6 expression.
\end{abstract}

Keywords: Trachinotus ovatus; fatty acid desaturases; PPAR $\alpha$ b and Fads6; transcriptional activity; heterologous expression

\section{Introduction}

Long-chain polyunsaturated fatty acids (LC-PUFA) are involved in numerous biological processes and are major components of complex lipid molecules [1]. In vertebrates, two LC-PUFA biosynthetic pathways are defined: the " $\Delta 6$ pathway" ( $\Delta 6$ desaturation-elongation- $\Delta 5$ desaturation) and the 
" $\Delta 8$ pathway" (elongation- $\Delta 8$ desaturation- $\Delta 5$ desaturation), which are initiated from $\alpha$-linolenic (C18:3n-3) and linoleic (C18:2n-6) acids, respectively [1-5]. Two sets of enzymes, the elongation of very long-chain fatty acids (Elovl) and fatty acyl desaturases (Fads), are involved in these pathways [6]. The Fads protein family include Fads1-6; however, only Fads2 and Fads6 have been characterized in vertebrate. The Fads2 enzyme has been widely studied in teleosts, especially in marine species [7-11]. Previous studies using yeast heterologous expression systems have indicated that Fads2 exhibits $\Delta 6$, $\Delta 5, \Delta 4$, and $\Delta 8$ activity in the biosynthetic pathway of LC-PUFAs [1,4,7-11]; however, little information on Fads6 has been reported. Ngoh et al. (2015) [12] revealed that fads6 expression was detected to be underlying, and suitable as a bioindicator to identify wild and farmed Lates calcarifer [1,2]. Some studies stated that Fads6 is involved with lipid and fatty acid metabolism in Homo sapiens [13,14]. Moreover, Fads6 displayed Fad synthesizing activity, but not Fad hydrolase activity, an activity which was localized to the N-terminal domain of full length Fads1 or 2 in H. sapiens [15]. However, the function of marine fish Fads6 appears ambiguous during LC-PUFA biosynthesis. It is also unclear whether the Fads6 gene possesses analogous fatty acid synthesis functions, as Fads2 in marine fish.

The peroxisome proliferator-activated receptor alpha (PPAR $\alpha)$ is a member of the steroid receptor superfamily of ligand-activated nuclear transcription factors, and is known to regulate lipid and glucose metabolism [16]. Lipid metabolism, including the inhibition of lipogenesis and the activation of fatty acid oxidation, is regulated by PUFA and their metabolites, along with transcription factors such as PPAR, hepatocyte nuclear factor-4 (HNF4), nuclear receptor subfamily 1 group $\mathrm{H}$ member 3 (NR1H3), sterol-regulatory element binding protein (SREBP), and nuclear factor-kappa B (NF-k B) [17]. PPAR $\alpha$ stimulates the expression of target genes, through direct binding to PPAR response elements (PPREs) in the promoter region of target genes [18,19]. Tang et al. [20] showed that PPAR $\alpha$ bound to the $\Delta 6$ desaturase promoter region significantly enhanced the transcription of $\Delta 6 \mathrm{Fad}$ in human hepatocytes (HepG2 cells). It was also shown that PPAR $\alpha$ upregulated Fads2 promoter activity in fish and avians [21,22]. Both PPAR $\alpha 1$ and PPAR $\alpha 2$ activated the promoter activity of Fads 2 in Latbrax japonicus, but no such regulatory activity was detected for Pseudosciaena crocea [21]. Moreover, it was suggested that PPAR $\gamma$ was a trans-acting factor that promoted $\Delta 6 / \Delta 5$ desaturase expression in the marine teleost Siganus canaliculatus [23]. Nevertheless, the role of PPAR $\alpha$ in the positive regulation of Fads6 remain largely unknown in fish.

The golden pompano Trachinotus ovatus (Linnaeus 1758), Carangidae, and Perciformes are found in the Asia-Pacific region and are important aquaculture fish in China due to their economic value [24,25]. T. ovatus muscle was found to be rich in PUFAs [26], meaning it is an ample source of endogenous PUFAs. Consequently, T. ovatus is an exceptional model in which to investigate LC-PUFA biosynthesis regulatory mechanisms. To investigate the underlying function of ToFads6 and the transcriptional regulation of PPAR $\alpha$ during LC-PUFA biosynthesis, this study sought to clarify the importance of PPAR $\alpha \mathrm{b}$ in regulating Fads 6 transcriptional activity. First, a functional characterization of the ToFads6 gene was performed using heterologous expression in yeast. Second, promoter activity assays were performed via the mutation of potential PPAR $\alpha \mathrm{b}$ binding sites to identify key element in the Tofads 6 promoter. Third, the overexpression (agonist) and suppression of expression (RNAi and inhibitors) of PPAR $\alpha \mathrm{b}$ was used to elucidate the transcriptional regulation of PPAR $\alpha \mathrm{b}$, with respect to ToFads6. Last, the role of the PPAR $\alpha \mathrm{b}$ M2 binding site in the Tofads6 promoter was investigated using the electrophoretic mobility shift assay (EMSA). These approaches helped identify Fad6 function in marine fish, and showed that PPAR $\alpha \mathrm{b}$ performed a vital function in Fads6 expression regulation. 


\section{Results}

\subsection{Molecular Cloning and Phylogenetics of T. ovatus Fads6}

The T. ovatus putative desaturase full length cDNA was $1594 \mathrm{bp}$ in length and included an ORF of $1143 \mathrm{bp}$. This nucleotide sequence translated to a peptide sequence of 380 amino acids (accession no. MG674450) (Figure S1). A Basic Local Alignment Search Tool (BLAST) analysis revealed that the ToFads6 protein sequence shared high sequence identity with Fads6 sequences from other teleosts, including the tilapia (Oreochromis niloticus, 85\%), stickleback (Gasterosteus aculeatus, 78\%), fugu (Takifugu rubripes, 76\%), and zebrafish (Danio rerio, $74 \%$ ), and low sequence identity with humans (Homo sapiens, 58\%).

Interestingly, comparisons of amino acid sequences for the Fads6 protein from these six species, revealed membrane-Fads-like domain and three regions ( $\mathrm{Ia}, \mathrm{Ib}$, and II) of conserved primary sequence, containing histidine-rich $\mathrm{HX}_{3} \mathrm{H}, \mathrm{HX}_{3} \mathrm{HH}$, and $\mathrm{HX}_{2} \mathrm{HH}$ motifs (Figure 1). Phylogenetic tree analysis indicated that ToFads6 clustered with several other Fads6 sequences from other osteichthyes, and more distantly, with amphibian, avian, and mammalian Fads6 (Figure 2). ToFads6 was grouped together with perciformes, such as $\mathrm{O}$. niloticus. The distributions and length of exons and introns from each Fads 6 gene are shown in Table S2. All Fads6 proteins contained six exons and five introns for all metazoans, except for the Tetraodon nigroviridis Fads6, which contained seven exons, while the Astyanax mexicanus Fads 6 contained five exons. Furthermore, the sizes of homologous introns sequences were different, while homologous exons sequences had almost no diversity.

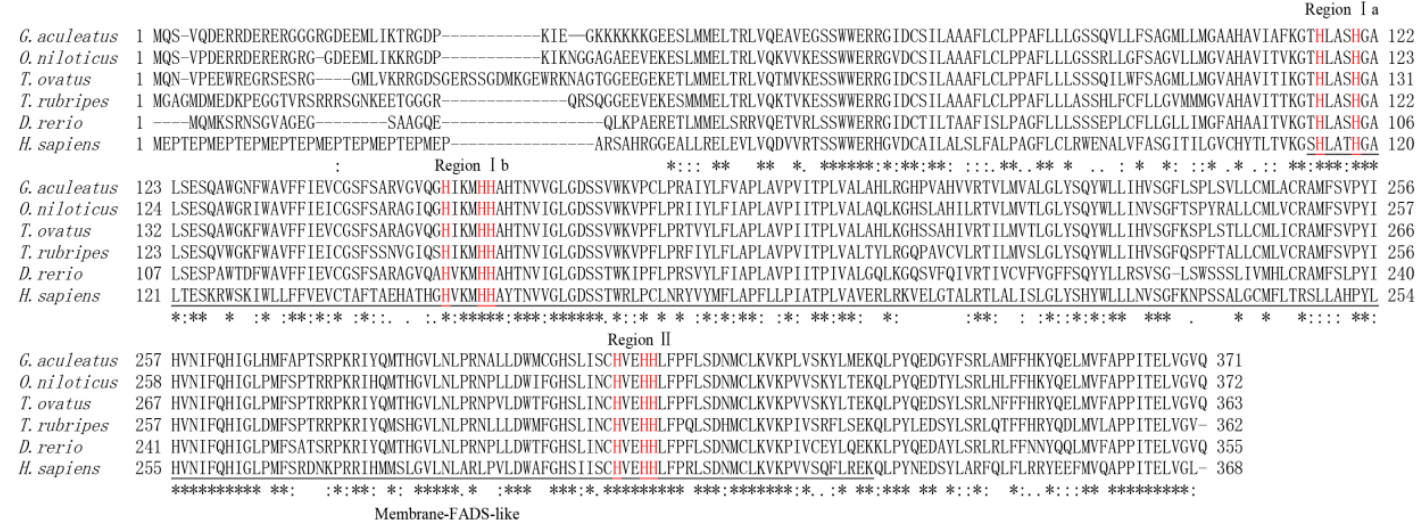

Figure 1. Amino acid sequences of Trachinotus ovatus Fads6 and with other homologs. Sequences comparisons revealed three regions of conserved histidine (his) cluster motifs containing eight his residues sites: HXXXH, HXXXHH, and HXXHH. Eight conserved his residues sites which are putative di-iron ligands are marked in red. Membrane-FADS-like domains are underlined. Accession numbers of Fads6 sequences are listed in Table S3. Identical and similar residues are marked with '*' and ' $:$ ', respectively. 


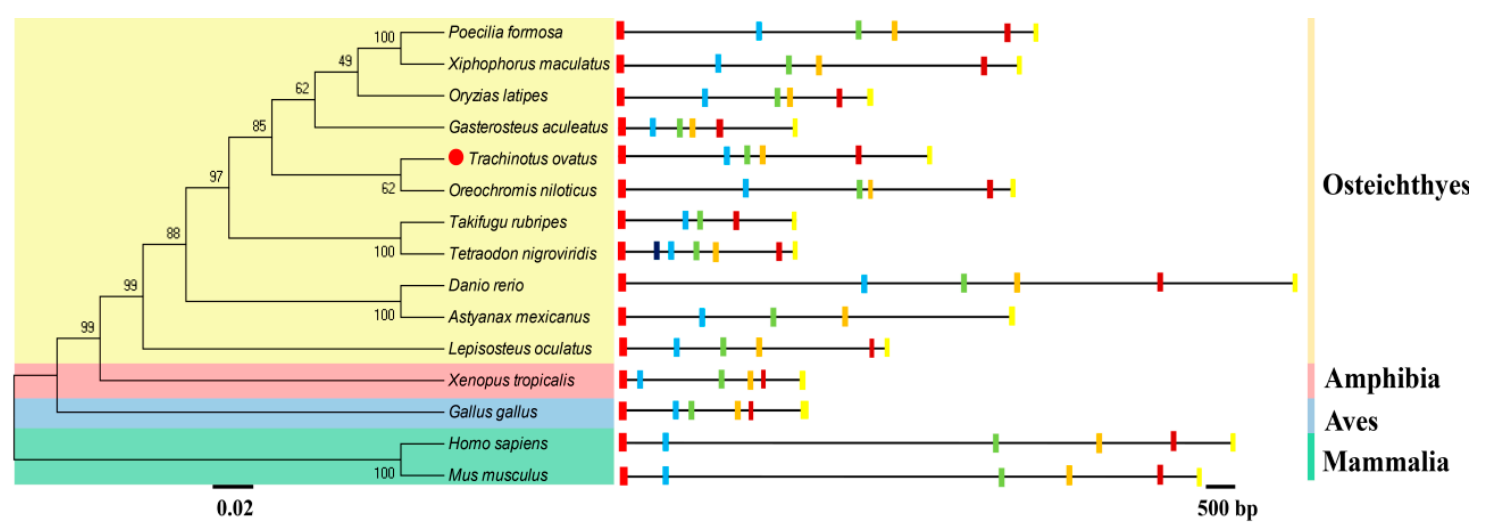

Figure 2. Genome structure analysis of ToFads6 genes according to the phylogenetic relationship. Exon and intron lengths of each PPAR $\alpha$ gene are displayed proportionally. Different color boxes and lines represent exons and introns, respectively. Identical color boxes represent homologous sequences.

\subsection{Heterologous Expression of the Desaturase ORF in Saccharomyces cerevisiae}

The function of ToFads6 was characterized by determining FA profiles in S. cerevisiae, transformed with pYES2-Fads6, and grown in the presence of potential FA substrates, such as C18:2n-6, C18:3n-3, C20:2n-6, C20:3n-6, C22:5n-3, and C22:4n-6. In yeast transformed with pYES2-Fads6 and grown in the presence of C20:2n-6 (peak 7) (Figure 3E), C20:3n-6, (peak 9) (Figure 3G), C22:4n-6, (peak 11) (Figure 3I), and C22:5n-3 (peak 13) (Figure 3K) however, additional FA peaks were identified as C20:3n-6 (peak 8) (Figure 3F), C20:4n-6 (peak 10) (Figure 3H), C22:5n-6 (peak 12) (Figure 3J), and C22:6n-3 (peak 14) (Figure 3L), based on gas chromatography (GC) retention times. From this data, it was concluded that the ToFads6 possessed $\Delta 4 / \Delta 5 / \Delta 8$ Fad activity. The conversion rates of C20:2n- 6 to C20:3n-6, C20:3n-6 to C20:4n-6, C22:4n-6 to C22:5n-6, C22:5n-3, to C22:6n-3 were calculated to be approximately $0.17 \%, 0.54 \%, 1.04 \%$, and $39.29 \%$, respectively (Table 1 ). Moreover, by using the gas mass spectrometry database, our results indicated that the C18:3n- 6 and C18:4n-3 mass spectrometry structures were not detected; however, C20:3n-6, C20:4n-6, C22:5n-6, and C22:6n-3 structures were observed (Figure S2). Additionally, this experiment showed ToFads6 had no $\Delta 6$ desaturase activity, as the yeast expressing the T. ovatus desaturase was unable to desaturate FA substrates, such as C18:2n-6 and C18:3n-3 (Table 1; Figure 3A-D).

Table 1. Conversion rates of pYES2-Fads6 transformed yeast grown in C18:2n-6, C18:3n-3, C20:2n-6, C20:3n-6, C22:5n-3, and C22:4n-6 substrates.

\begin{tabular}{cccc}
\hline FA Substrate & Product & Conversion (\%) & Activity \\
\hline C18:2n-6 & C18:3n-6 & 0 & $\Delta 6$ \\
C18:3n-3 & C18:4n-3 & 0 & $\Delta 6$ \\
C20:2n-6 & C20:3n-6 & $0.17 \pm 0.02$ & $\Delta 8$ \\
C20:3n-6 & C20:4n-6 & $0.54 \pm 0.06$ & $\Delta 5$ \\
C22:5n-3 & C22:6n-3 & $39.29 \pm 4.4$ & $\Delta 4$ \\
C22:4n-6 & C22:5n-6 & $1.04 \pm 0.11$ & $\Delta 4$ \\
\hline
\end{tabular}

Conversions are expressed as a percentage of total FA substrate converted to desaturated products. 

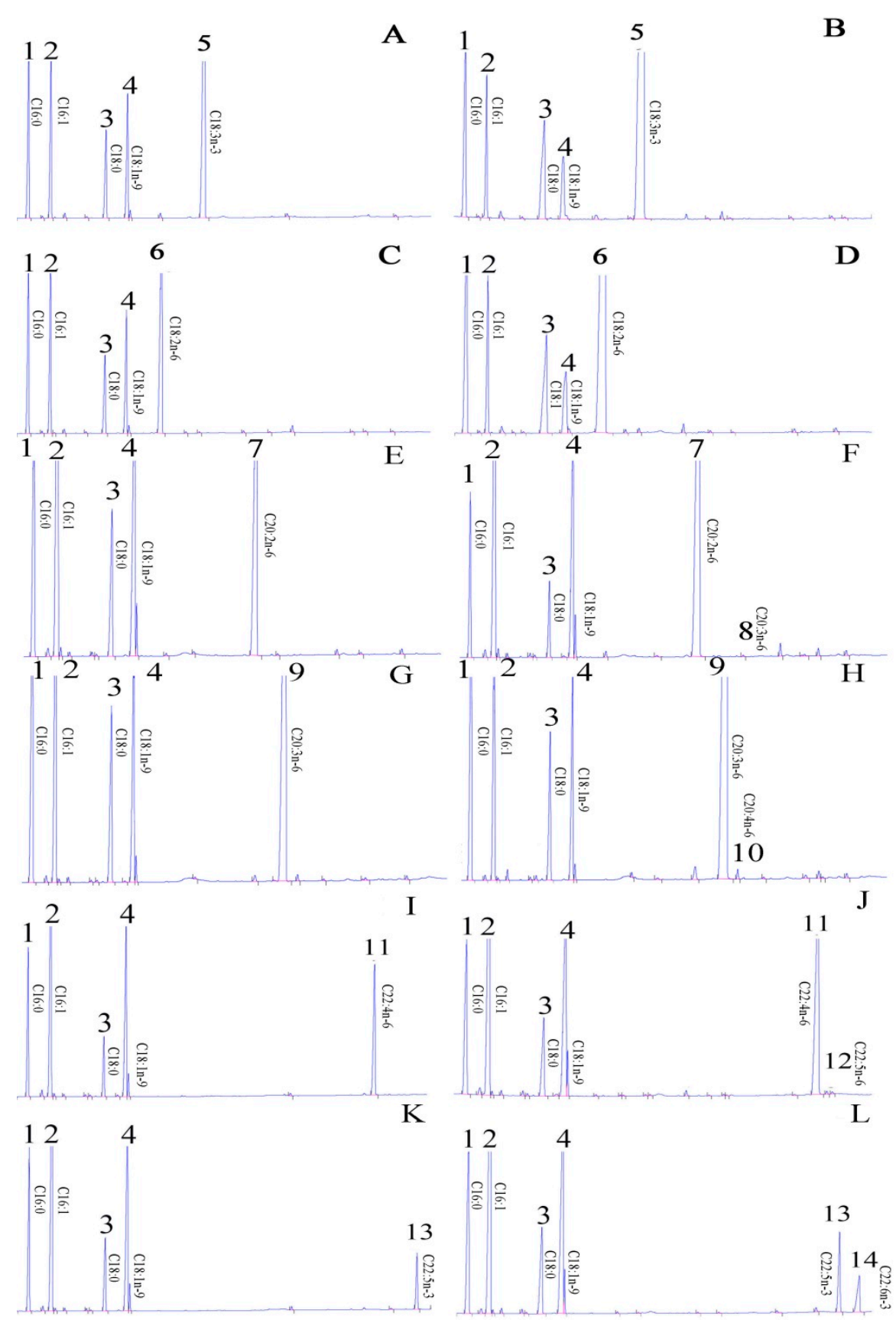

Figure 3. Functional characterization of the putative ToFads6 in transgenic yeast. Fatty acid methyl esters (FAMEs) are extracted from yeast transformed with pYES2-Fads6, and grown in the presence of PUFA substrates C18:3n-3 (A), C18:2n-6 (C), C20:2n-6 (E), C20:3n-6 (G), C22:4n-6 (I), and C22:5n-3 (K). All left panels are yeast cells with empty vector. Based on retention times, additional peaks were identified as C18:3n-3 (B), C18:2n-6 (D), C20:3n-6 (F), C20:4n-6 (H), C22:5n-6 (J), and C22:6n-3 (L). Peaks 1-4 represent the main endogenous FAs in yeast, namely C16:0, C16:1 isomers, C18:0, and C18:1n-9, respectively. Moreover, peaks 5-14 represent exogenously supplemented FAs and the corresponding desaturation products, including C18:3n-3 (5), C18:2n-6 (6), C20:2n-6 (7), C20:3n-6 (8), C20:3n-6 (9), C20:4n-6 (10), C22:4n-6 (11), C22:5n-6 (12), C22:5n-3 (13), and C22:6n-3 (14), respectively.

\subsection{Tissue Distribution of ToFads6}

Tissue distributions of ToFads 6 were delineated by qRT-PCR. The highest ToFads 6 mRNA levels were detected in the brain, followed by the small intestine and the female gonads and relatively 
low ToFads6 expression levels were observed in fin, gill, blood, and kidney (Figure 4). Notably, the expression of ToFads6 in the brain was much higher than in other tissues $(p<0.05)$.

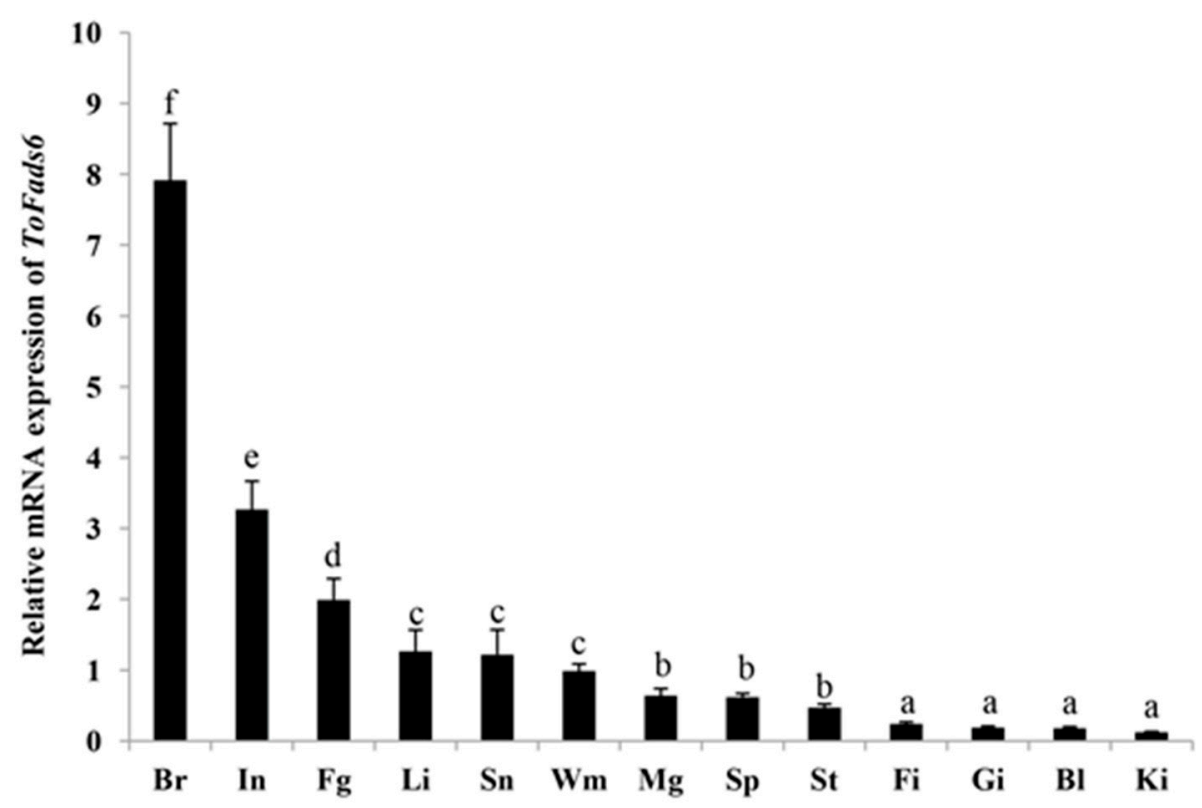

Figure 4. Gene transcriptions of ToFads6 in various tissues. The tissues are small intestine (In), head-kidney $(\mathrm{Ki})$, white muscle $(\mathrm{Wm})$, stomach $(\mathrm{St})$, female gonad $(\mathrm{Fg})$, male gonad $(\mathrm{Mg})$, brain $(\mathrm{Br})$, liver ( $\mathrm{Li})$, gill $(\mathrm{Gi})$, spleen $(\mathrm{Sp})$, fin $(\mathrm{Fi})$, blood $(\mathrm{Bl})$, and snout $(\mathrm{Sn})$. Different letters refer to significant differences.

\subsection{Promoter Analysis of PPARab Regulation}

The cloned candidate ToFads6 promoter (2372 bp) was an upstream nontranscribed sequence. To determine the binding region of PPAR $\alpha \mathrm{b}$ in the ToFads6 promoter, a full-length candidate promoter and several truncated mutants were constructed with a promoter-less luciferase reporter vector, pGL3-basic. The promoter construct, Fads6-p5 ( $-448 \mathrm{bp}$ to $+1 \mathrm{bp})$ showed the highest promoter activity with PPAR $\alpha$ b, suggesting that this region of the Fads6-p5 promoter sequence contained the PPAR $\alpha \mathrm{b}$ binding site (Figure 5). To identify the PPAR $\alpha \mathrm{b}$ binding sites in the ToFads 6 promoter, the predicted binding sites were mutated (Figure 6A, Table 2). The effects on promoter activity were investigated in 293T cells, transfected with each mutant and PPAR $\alpha$ b. The results revealed that mutation of the $\mathrm{M} 2$ binding site $(-113 \mathrm{bp}$ to $-87 \mathrm{bp})$ caused significant reduction in promoter activity (Figure 6B), showing that M2 was the PPAR $\alpha$ b binding site in the ToFads6 promoter. Notably, three other predicted binding sites did not induce luciferase activity with PPAR $\alpha \mathrm{b}$, suggesting that these three sites were not required for triggering ToFads6 expression with PPAR $\alpha \mathrm{b}$. 


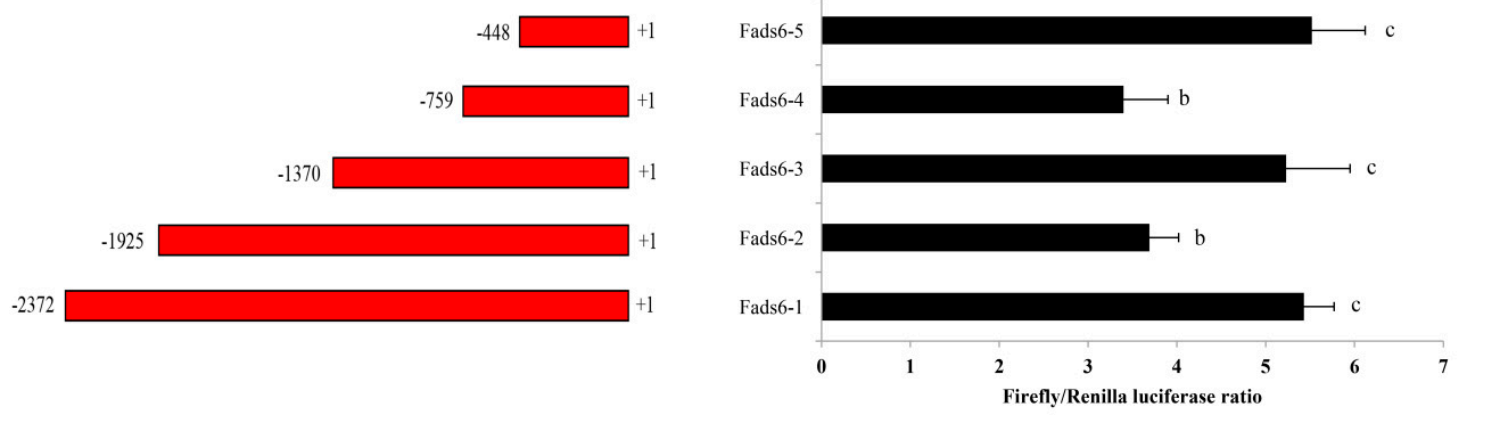

Figure 5. Promoter activity analysis of ToFads6. pGL3-Basic-Fads6s were cotransfected with the transcription factor PPAR $\alpha$ b into 293 T cells. All values are presented as the mean \pm SD $(n=3)$. Asterisks indicate different values, with respect to controls $\left({ }^{*} p<0.05\right.$ and $\left.{ }^{* *} p<0.01\right)$. Bars on the same group with different letters are statistically significant from one another.

A

GGGGGTGAACGACATGCAGAATGTATGAGACACCAGAGAGGAGGGAGAAGTCG ACTCCGGGCTGAGCAGCTGCAGTTTTGTGTGGCTGCTTGTGTGAGGATTTGTGGA TCCATAACATCACATGGCAGACTTACATCTTCATGCCATGGGACAATAAATTCCT

CTGCTGCTGGaCTGCATCAAGAGTCAGCTGACAAGGGGGGGAaCAGAGGAGAGG AAGAGGAAGAGAGATGAGGAGGAGGAGGTAAGAGAGGAGGTTCCACGAGGCTC

TTGAAGTAGCAGGAAGGGGGCTGGGCTTCTCTGACAATGCTTCAAACCAATAAG

GACTTTCGCAATGCTAACTTTGACCTGTGGACTGTGCAGCATTTAGCACCAGCTG

CCTGCAAGAGGACACAACCTGCACGGTGACTTTTTGTTTTGAGCCGGTTCATCAG

\section{CAGAGGCAACTGAC}

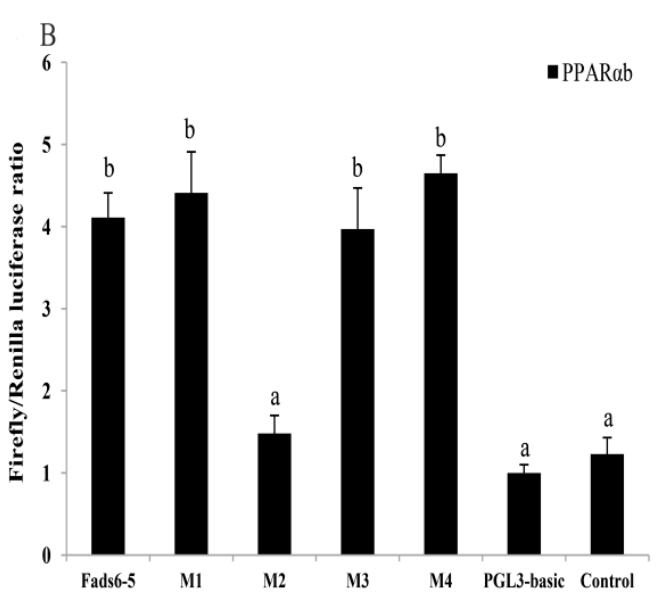

Figure 6. The nucleotide sequence and predicted binding sites for transcription factors in the core ToFads6 promoter region (A). Effects of transcription factor mutations on ToFads6-5 promoter activity (B). Binding sites are shown with boxes M1-M4. Mutations in promoter sequences are listed in Table 2. All values are presented as the mean $\pm \mathrm{SD}(n=3)$. Asterisks indicate values are different from controls $\left({ }^{*} p<0.05\right.$ and $\left.{ }^{* *} p<0.01\right)$. Bars on the same group with different letters are statistically significant from one another.

Table 2. Primers used for site-directed mutagenesis of putative binding sites in the ToFads6 promoter.

\begin{tabular}{ccc}
\hline Putative Binding Sites & Nucleotide Sequence & Mutation \\
\hline M1 & 5' CTGGACTGCATCAAGAGTCA 3' $^{\prime}$ & deletion \\
M2 & 5' ATGCTAACTTTGACCTGTGGACTGTGC 3' & deletion \\
M3 & 5' AGCAGCTGCAGTTTTGTGTG 3' & deletion \\
M4 & 5' GGGGGGAACAGAGGAGAGG 3' & deletion \\
\hline
\end{tabular}

\subsection{Transcriptional Regulation of ToFads6 by PPAR $\alpha b$}

Protein and mRNA levels of ToPPAR $\alpha b$ were significantly decreased in a time-dependent manner by RNAi knockdown of PPAR $\alpha b$, suggesting effective knockdown of ToPPAR $\alpha b$ expression in T. ovatus caudal fin (TOCF) cells (Figure 7A,C) [27]. When ToPPAR $\alpha b$ expression was reduced, protein and mRNA levels of ToFads6 were dramatically depleted, when compared with the control group at the 
corresponding time points (Figure 7B,D). Moreover, PPAR $\alpha$ b-mediated agonist activity (WY-14643) dramatically increased ToFads 6 mRNA levels $(p<0.05)$ (Figure 7E), and similarly the expression of ToFads6 was dramatically suppressed upon addition of the PPAR $\alpha \mathrm{b}$ inhibitor, GW6471 in a concentration-dependent manner, over a $24 \mathrm{~h}$ stimulation period (Figure $7 \mathrm{~F}$ ). These results suggested an active regulatory role of ToPPAR $\alpha b$ on ToFads6 expression in TOCF cells.

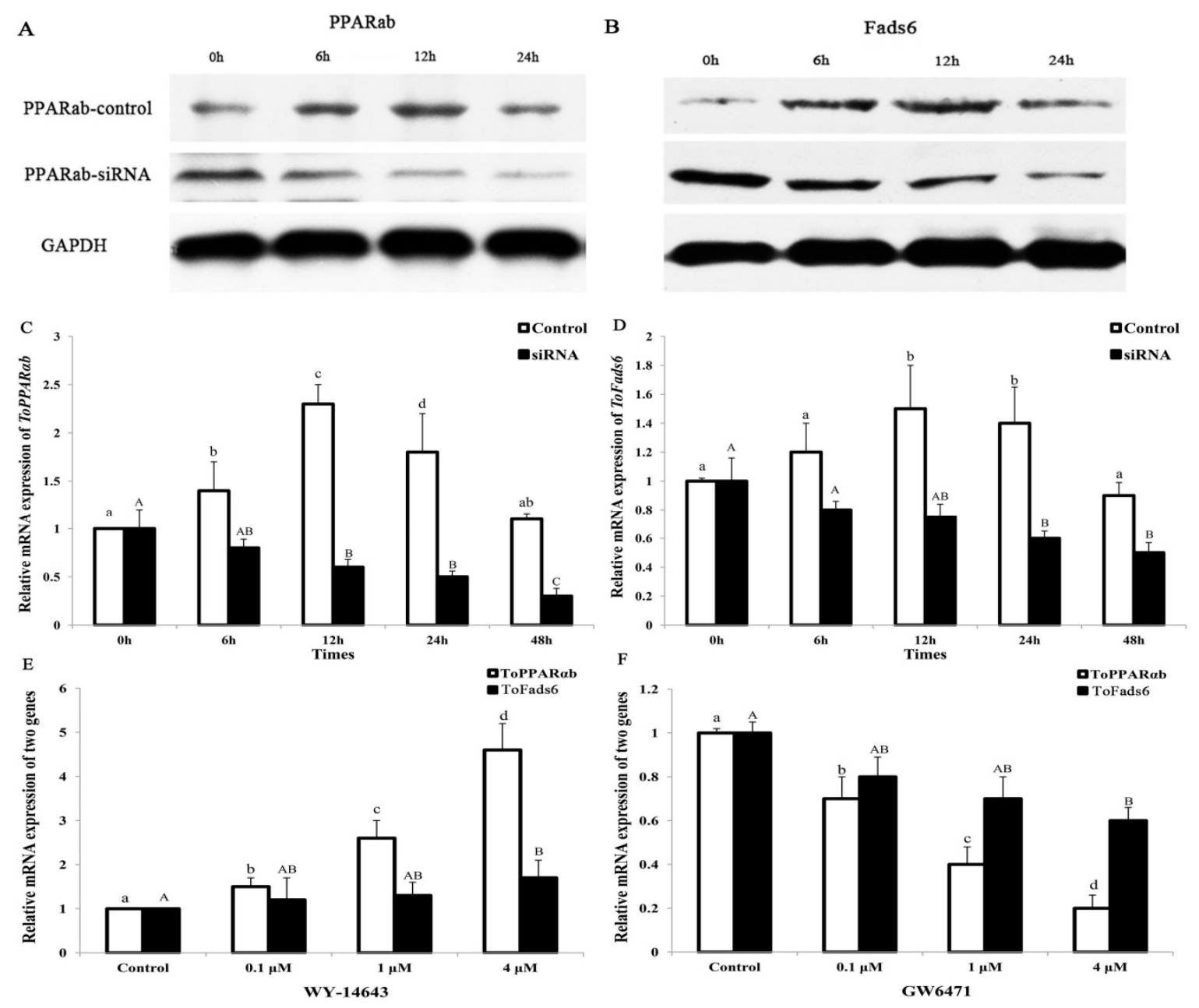

Figure 7. ToPPAR $\alpha b$ upregulates ToFads6 expression. Western blot and real-time PCR analysis were used to detect ToPPAR $\alpha b$ expression $(\mathbf{A}, \mathbf{C})$ and ToFads6 expression (B,D) after the transfection of either control RNA (control) or siRNA (RNAi), respectively. TOCF cells were stimulated with $0.1,1$, and $4 \mathrm{mM}$ of PPAR $\alpha$ b agonist (WY-14643) (E) and inhibition (GW6471) (F) for $24 \mathrm{~h}$. The expression of ToPPAR $\alpha b$ and ToFads 6 was dramatically increased and decreased in a concentration-dependent manner, respectively. ToPPAR $\alpha$ b expressions were described as Zhu et al. [27]. All values were expressed as the mean \pm SD $(n=3)$. Bars on the same group with different letters are statistically significant from one another $(p<0.05)$.

\subsection{Binding of PPAR $\alpha b$ to Fads6 Promoters}

To confirm the PPAR $\alpha \mathrm{b}$ binding motif in the ToFads6 promoter, an EMSA assay was performed. Based on the predicted ToPPAR $\alpha \mathrm{b}$ binding site, oligonucleotide probes were synthesized and incubated with HEK293T cell lysates, including recombinant PPAR $\alpha b$ in vitro. Recombinant PPAR $\alpha b$ bound to the oligonucleotide probes of the predicted PPAR $\alpha \mathrm{b}$ binding site in the ToFads6 promoter; however, mutations in the PPAR $\alpha$ b binding site (Table S1), resulted in the dissociation of the DNA-rPPAR $\alpha b$ complex (Figure 8), suggesting that PPAR $\alpha \mathrm{b}$ was specifically interacting with the M2 motif in the 
ToFads 6 promoter. The formation of a DNA-rPPAR $\alpha$ b complex was specific, since it could only be blocked by excessive unlabeled control probes $(100 \times)$.

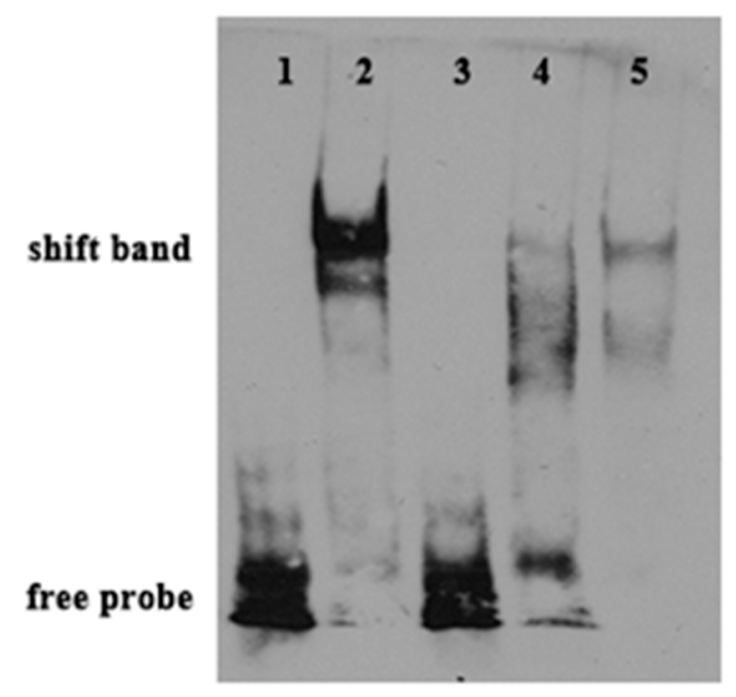

Figure 8. Binding reactions of ToPPAR $\alpha \mathrm{b}$ and ToFads6 promoters. Biotin-labeled electrophoretic mobility shift assay (EMSA) probes were incubated with HEK293T lysates containing recombinant PPAR $\alpha$ b protein. WT, wild-type probe; MT: mutated probe. 1, Fads6-WT; 2, Fads6-WT+Protein; 3, Fads6-WT+Flag; 4, Fads6-WT (cold 100×) + Protein; 5, Fads6-MT + protein.

\section{Discussion}

This study has generated insights into mechanisms underlying the transcriptional regulation of LC-PUFA biosynthesis in T. ovatus. To achieve this, the sequence and functional characterization, tissue expression patterns, and transcriptional regulation of ToFads 6 were investigated. The ToFads 6 ORF encoded a protein that was $74-85 \%$ identical to Fads6 proteins from other teleosts. These proteins contained three classical histidine-rich structural motifs: (i) $\mathrm{HX}_{3} \mathrm{H}$, (ii) $\mathrm{HX}_{3} \mathrm{HH}$, and (iii) $\mathrm{HX}_{2} \mathrm{HH}$ boxes, which are present in membrane-bound desaturase domains. These three conserved histidine-rich boxes are also present in other Fads2 proteins from other species, and are believed to be essential for binding iron ligands, for enzyme activity [11,28-31]. Phylogenetic analysis showed a typical phylogeny, revealing the amino acid sequence of ToFads6 closely matched the Fads6 of O. niloticus, but then appeared to separate from other fish, amphibians, avian and mammalian species. A genome structure analysis indicated that all Fads6s contained six exons and five introns in metazoans, except for Fads6 from T. nigroviridis and A. mexicanus. These observations may represent intron gain or loss during evolutionary processes [32].

Two members of the Fads protein family have been described in teleosts: Fads2 and Fads6. For marine fish, yeast heterologous expression systems indicated that Fads 2 showed $\Delta 4 / 5 / 6 / 8$ activity in LC-PUFA biosynthesis [1,4,7-11], however, no information was available on the underlying function of Fads6. In this study, the functional characteristics of T. ovatus Fads6, via heterologous expression in S. cerevisiae, indicated that the T. ovatus putative desaturase was Fads6, with $\Delta 4$ desaturation activity. This was functionally similar to the Fads6 from Arabidopsis thaliana, Medicago truncatula, and Homo sapiens [12-14]. T. ovatus Fads6 exhibited low activity towards 22:4n-6 and 22:5n-3 substrates, such as 22:5n-6 (1.04\%) and 22:6n-3 (39.29\%). These results were similar to freshwater and marine fish, such as $10.2 \%$ and $3.6 \%$ in Channa striata [33], $14.0 \%$ and $23.0 \%$ in Siganus canaliculatus [8], $16.1 \%$ and $6.8 \%$ in Solea senegalensis [34], $13.7 \%$ and $24.1 \%$ in O. latipes, and $8.1 \%$ and $10.8 \%$ in O. niloticus, for Fads2 with $\Delta 4$ desaturation activity [35]. It was also suggested that an equivalent highly unsaturated fatty acid (HUFA) synthesis activity of ToFads 6 was observed in other teleosts Fads2, which exhibited $\Delta 4$ desaturation activity. Nevertheless, teleost Fads 2 did not exhibit the above functions in the biosynthesis 
of saturated LC-PUFA [29,36,37]. Two LC-PUFA biosynthesis pathways from $\alpha$-linolenic (C18:3n-3) and linoleic (C18:2n-6) acids have been proposed for T. ovatus [4,8,35].

In this study, the highest ToFads6 mRNA expression was detected in the brain, showing that essential fatty acid metabolism occurs there [38]. However, relatively moderate ToFads6 mRNA expression levels were detected in the intestine and liver. Interestingly, these are the first tissues exposed to dietary lipids and they are the main lipid metabolism tissues in the body [38]. Moreover, the liver is the main site for LC-PUFA synthesis [39]. These data indicated that lower levels of hepatic Fads6 transcripts in carnivorous marine fish, like T. ovatus, may correlate with their limited LC-PUFA biosynthetic abilities [3].

In general, the mRNA levels of some genes in eukaryotic cells are dependent on transcription factors and RNA polymerases binding to specific sequences in gene promoters [40]. Consequently, the integrity and activity of a promoter can affect gene expression. Moreover, the transcription factor PPAR $\alpha$ regulates lipid metabolism in mammals, and also influences transcription of the Fads gene family in fish and avian species [16,21-23]. Notably, evidence has suggested that Fads2 promoter activity was increased by PPAR $\alpha$ in fish and avian species [21,22]. Dual-luciferase reporter assays were conducted to clarify regulatory mechanisms, where PPAR $\alpha \mathrm{b}$ was believed to modulate Fads6 expression. The analysis of truncated mutants indicated that ToFads6 reporter activity was induced by the overexpression of PPAR $\alpha \mathrm{b}$. The core binding region in the ToFads 6 promoter was $-448 \mathrm{bp}-+1 \mathrm{bp}$ (Figure 5). This is the first evidence showing that the transcription of ToFads 6 can be upregulated by PPAR $\alpha b$. Furthermore, the deletion of the PPAR $\alpha \mathrm{b}$ M2 binding site ( $-113 \mathrm{bp}$ to $-87 \mathrm{bp}$ ) resulted in significantly reduced promoter activity (Figure 6), suggesting that the PPAR $\alpha \mathrm{b}$ M2 binding site was essential for ToFads6 promoter activity.

To further confirm whether PPAR $\alpha \mathrm{b}$ was a transcription factor implicated in ToFads 6 function, the effects of PPAR $\alpha$ b knockdown on ToFads 6 mRNA expression were investigated by qRT-PCR and western blotting in TOCF cells. These data showed that PPAR $\alpha \mathrm{b}$ upregulated both ToFads6 mRNA and protein levels. Moreover, the PPAR $\alpha \mathrm{b}$ agonist (WY-14643) enhanced ToFads6 transcription and consequently increased ToFads6 mRNA, whereas PPAR $\alpha \mathrm{b}$ inhibition with GW6471, showed the opposite effects (Figure 7). Those results showed that both Fads2 and Fads6 expressions were controlled by PPAR $\alpha \mathrm{b}$. The EMSA assay further demonstrated that PPAR $\alpha$ b specifically bound to the ToFads 6 promoter at the M2 binding site (Figure 8).

In summary, the functional studies presented here have shown that ToFads6 may effectively desaturate 22:4n-6 and 22:5n-3 substrates. Moreover, the proposed synthesis pathway of LC-PUFA was in T. ovatus (Figure 9). Furthermore, ToFads6 expression was positively regulated by the transcription factor, PPAR $\alpha \mathrm{b}$. The EMSA assays further showed that PPAR $\alpha \mathrm{b}$ bound effectively to the M2 binding site in the ToFads6 promoter. Thus, a positive feedback mechanism, mediated by Fads6-induced PPAR $\alpha b$ activation, is proposed in T. ovatus. PPAR $\alpha$ b plays an important role in ToFads 6 regulation and may accelerate the biosynthesis of LC-PUFA through the upregulation of ToFads6 transcription. These results provide new insights into the regulation and function of Fads 6 in fish and further reveal the complexity of associated regulatory mechanisms. 


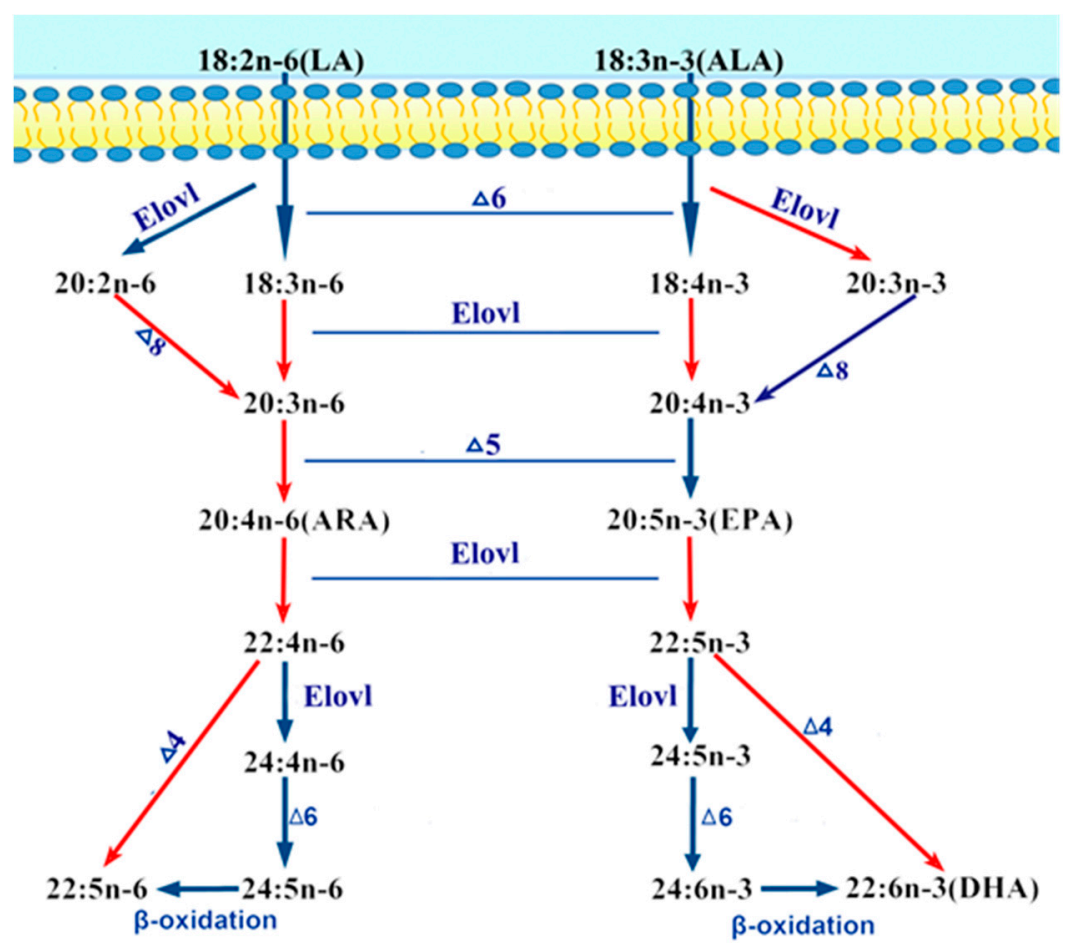

Figure 9. The proposed synthesis pathway of PUFA in T. ovatus. Red arrows represent the pathway confirmed in T. ovatus [27], blue arrows indicate the pathway confirmed in other marine fish $[8,10,23]$.

\section{Materials and Methods}

\subsection{Ethics Statement}

This study was performed in strict accordance with the guide for the Animal Care and Use Committee of South China Sea fisheries Research Institute, Chinese Academy of fishery Sciences (No.SCSFRI96-253, 5th sep 2015) in China.

\subsection{Animals and Tissue Collection}

T. ovatus juvenile fish (body weight: $62 \pm 8.5 \mathrm{~g}$ ) were collected from Linshui Marine Fish Farm in Hainan Province, China. The fish were raised on commercial feed (Hengxin, guangzhou, China, crude protein $>37 \%$, crude fat $>7 \%$ ) according to standard feeding schemes 2 weeks before sampling, and maintained in fresh seawater at $22 \pm 1{ }^{\circ} \mathrm{C}$, in dissolved oxygen $>6 \mathrm{mg} / \mathrm{L}$, under a recirculating aquaculture system. For the study, fish tissue $(n=6)$ containing small intestine, liver, white muscle, brain, spleen, fin, gill, head kidney, stomach, blood, and male and female gonads were sampled, then flash frozen in liquid nitrogen, and stored at $-80^{\circ} \mathrm{C}$ until further use.

\subsection{Gene Cloning and Bioinformatics of T. ovatus Fads6}

Total RNA $(1 \mu \mathrm{g})$ was extracted from T. ovatus liver by TRIzol Reagent (Takara, Kyoto, Japan). Subsequently, cDNA was synthesized using the Prime ScriptTM RT reagent Kit (Takara), according to the manufacturer's instructions. According to genomic data of T. ovatus (Accession No. PRJEB22654 under the European Nucleotide Archive (ENA); Sequence Read Archive under BioProject PRJNA406847), a putative ToFads6 sequence was obtained. To determine the veracity of the putative Fads6 sequence, gene specific primers were designed (Table S1). The PCR protocol used was described previously [41]. The amplified products were purified using a DNA Purification Kit (Tiangen, Beijing, China), ligated into the pEASY-T1 vector (TransGen Biotech, China), and sequenced (Invitrogen, Shanghai, China). Validated plasmids were transformed into competent Trans1-T1 cells 
(TransGen Biotech, Beijing, China). A Blast search on the putative Fads6 ORF sequence further confirmed accuracy and validity.

The deduced amino acid sequence of the cloned ToFads6 open reading frame (ORF) was aligned with other Fads6 ortholog ORFs from Takifugu rubripes (XP_003961115.2), Tetraodon nigroviridis (CAG03043.1), Gasterosteus aculeatus (ENSGACG00000014468), Poecilia formosa (XP_007570697.1), Xiphophorus maculatus (XP_005794734.1), Oryzias latipes (XP_023805434.1), Oreochromis niloticus (XP_005453754.1), Danio rerio (XP_003199708.1), Astyanax mexicanus (XP_022518693.1), Lepisosteus oculatus (XP_006635501.1), Homo sapiens (NP_835229.3), Mus musculus (NP_828874.3), Gallus gallus (XP_426241.2), and Xenopus tropicalis (XP_002939607.1). Multiple sequence alignments were conducted using ClustalX version 2.0 (Dublin, Ireland), with default parameters [42]. Phylogenetic analyses for all Fads6 amino acid sequences were performed using maximum likelihood (ML) methods (LG $+G$ model, bootstrap 1000), with MEGA 6.0 [43]. All available Fads6 genome sequences were downloaded from public databases: Ensembl (http:/ /asia.ensembl.org/) and Genome Browser (http:/ / genome.ucsc.edu/cgi-bin/hgBlat). The phylogenetic tree and genome structures were embellished using FigTree v1.4.2 (http:/ / tree.bio.ed.ac.uk/software/figtree/) and Adobe PhotoShop CS6 (Adobe, San Jose, CA, USA).

\subsection{Functional Characterization of the ToFads6 Desaturase}

PCR products corresponding to the ToFads6 ORF were amplified from T. ovatus liver cDNA using high fidelity Pfu DNA polymerase (Promega, Madison, Wis, USA) with primers incorporating Hind III and Xho I enzyme restriction sites (Table S1). The PCR products were digested with the above restriction endonucleases (Takara, Kyoto, Japan) and ligated into a similarly digested pYES2 yeast expression vector (Invitrogen, Shanghai, China). The recombinant plasmid (pYES2-Fads6) was transformed into Saccharomyces cerevisiae-competent cells (S.c. EasyComp Transformation Kit, Invitrogen). The selection of recombinant yeast colonies and subsequent yeast culture was prepared according to previously published methods [44,45]. Fatty acids (FA), designated as C18:2n-6 (Linoleic acid), C18:3n-3 ( $\alpha$-linolenic acid), C20:2n-6 (Eicosadienoic acid), C20:3n-6 (Dihomo- $\gamma$-linolenic acid), C22:4n-6 (Adrenic acid), and C20:5n-3 (Eicosapentaenoic acid, EPA) were used as substrates for detecting desaturase activity of ToFads6. The final concentrations of FA substrates varied according to their fatty acyl chain lengths: $0.5 \mathrm{mM}(\mathrm{C} 18)$ and $0.75 \mathrm{mM}$ (C20). Yeast cultures were incubated for two days at $30{ }^{\circ} \mathrm{C}$, harvested, and washed twice, as described previously [8]. As a control, yeast were transformed with pYES2 only (no insert) and treated similarly. Fatty acid methyl esters (FAMEs) were prepared, extracted, purified and analyzed by thin-layer chromatography (TLC) and gas chromatography (GC2010-plus; Shimadzu, Kyoto, Japan) as described previously [46]. The proportion of substrate fatty acids converted to desaturated FA products was calculated as follows, (product area/(product area + substrate area) $\times 100$ [8].

\subsection{Real-Time Quantitative PCR Analysis}

Specific primers for real-time quantitative PCR (qRT-PCR) were designed by Primer Premier 5.0 (Premier Biosoft, Palo Alto, CA, USA) based on cloned nucleotide sequences (Table S1). The translation elongation factor 1-alpha $(E F 1 \alpha)$ and PPAR $\alpha \mathrm{b}$ were verified by sequencing and were used as a reference and target gene, respectively $[27,47]$. The qRT-PCR amplifications were performed in a quantitative thermal cycler (Mastercycler EP Realplex, Eppendorf, Hamburg, Germany). The program parameters were $95{ }^{\circ} \mathrm{C}$ for $2 \mathrm{~min}$, followed by 40 cycles of $95{ }^{\circ} \mathrm{C}$ for $10 \mathrm{~s}, 56{ }^{\circ} \mathrm{C}$ for $10 \mathrm{~s}$, and $72{ }^{\circ} \mathrm{C}$ for $20 \mathrm{~s}$. Amplification efficiencies of target and reference genes were observed from the slope of the log-linear portion of the calibration curve, with PCR efficiency $=10^{(-1 / \text { Slope })}-1$. Target gene expression levels were calculated using the $2^{-\Delta \Delta \mathrm{Ct}}$ method [48]. 


\subsection{Preparation of a Fads6 Polyclonal Antibody and Western Blotting Analysis}

To prepare the polyclonal anti-Fads6 antibody, a specific domain (Fads6 ${ }^{\text {aa257-380 }}$ ) of Fads6 was amplified using gene-specific primers (Table S1). The resulting PCR product was inserted into the pET-B2M vector using Nde I/Xho I sites. To express recombinant T. ovatus Fads6 protein (rToFads6), the recombinant plasmid was transformed into Escherichia coli BL21 (DE3) (Novagen, Darmstadt, Germany). The rToFads6 was purified as described previously [49]. To generate a polyclonal antibody, purified rToFads6 protein was injected into white New Zealand rabbits using standard methods [50]. Once generated, the polyclonal antibody was pre-adsorbed using E. coli lysate supernatants to eliminate inhomogeneous antibodies and depurated on a HiTrapTM Protein A HP column on a AKTAprime ${ }^{\mathrm{TM}}$ Plus system (GE Healthcare, Boston, MA, USA).

To confirm specificity of the rabbit anti-Fads6 antibody, human embryonic kidney (HEK293T) cells were transfected with pcDNA3.1 and pcDNA3.1-Fads6 for $48 \mathrm{~h}$. After this period, cells were harvested by centrifugation at $160 \times g$ for $10 \mathrm{~min}$ at $4{ }^{\circ} \mathrm{C}$. Total protein was extracted using ProteoPrep ${ }^{\circledR}$ Total Extraction Sample Kit (Sigma-Aldrich, St. Louis, Mo, USA). This protein was electrophoresed on $12 \%$ SDS-PAGE and electrophoretically transferred to polyvinylidene fluoride (PVDF) membranes (Millipore, Billerica, MA, USA) using the PierceG2 Fast Blotter (25 V for 10 min, Pierce, Rockford, IL, USA). Western blotting analyses were executed according to a previously described protocol [51].

To observe endogenous Fads6 expression, TOCF cells were transfected with PPAR $\alpha \mathrm{b}$ siRNA, cells were harvested and lysed as described previously [27,52]. Total protein was incubated with/without calf intestinal alkaline phosphatase (CIAP) $(20 \mathrm{U})$ at $37^{\circ} \mathrm{C}$ for $30 \mathrm{~min}$, separated by $12 \%$ SDS-PAGE and transferred to PVDF membranes using the PierceG2 Fast Blotter. Primary antibodies, anti-Fads6, murine anti-Flag (Sigma-Aldrich, St. Louis, MO, USA), the loading control $(1 ; 1000)$, and the anti-glyceraldehyde 3-phosphate dehydrogenase antibody (GAPDH; Sigma-Aldrich) were incubated with the PVDF membrane in 1\% $(w / v)$ nonfat milk in Tris-buffered saline and Tween 20 (TBST) buffer ( $0.1 \%$ Tween 20$)$ for $3 \mathrm{~h}$. Horse radish peroxidase-(HRP)-conjugated goat anti-rabbit antibody (1:3000) was used as a secondary antibody (Sigma-Aldrich). The results were observed using an electrochemiluminescence (ECL) system (Tanon, Shanghai, China).

\subsection{Cloning of the Fads6 Promoter and Construction of Deletion Mutants}

Genomic DNA was extracted from the muscle tissue of T. ovatus, as described previously [53], and used as a template for candidate promoter cloning. The sequence upstream of the Fads 6 gene was obtained from genomic sequencing data of T. ovatus. To identify the core promoter region of ToFads6, the forward primers (Fads6-p1F, Fads6-p2F, Fads6-p3F, Fads6-p4F, and Fads6-p5F), were designed with a $5^{\prime}$ Hind III site, and the common reverse primer (Fads6-pR) was designed with a $3^{\prime}$ Xho I site (Table S1). These primers were used to obtain a full-length promoter fragment (Fads6-p1, 2372 base pairs (bp)) and four truncated fragments: (i) Fads6-p2, 1925 bp; (ii) Fads6-p3, 1370 bp; (iii) Fads6-p4, 759 bp; and (iv) Fads6-p5, 448 bp (Figure 5). The truncated mutants were amplified using PrimeSTAR Master Mix (Takara, Japan). The program parameters were $95^{\circ} \mathrm{C}$ for $4 \mathrm{~min}$, followed by 30 cycles of $95^{\circ} \mathrm{C}$ for $40 \mathrm{~s}, 56^{\circ} \mathrm{C}$ for $40 \mathrm{~s}$, and $72^{\circ} \mathrm{C}$ for $1 \mathrm{~min}$. A general DNA Purification Kit (Tiangen, China) was used to purify the PCR products. All purified PCR products and a pGL3-basic (Promega, USA) vector were digested with Hind III and Xho I, and concentrated by T4 DNA ligase (Takara, Japan) overnight at $16^{\circ} \mathrm{C}$. Recombinant plasmids were extracted using EndoFree Plasmid Giga Kit (Tiangen, China), and constructs were confirmed by sequencing, as described above.

\subsection{Construction of Truncated Mutants for the Identification of Predicted Transcription Factor (TF) Binding Sites in the Fads6 Promoter}

To determine the potential function of PPAR $\alpha \mathrm{b}$ binding sites on the core Fads6 promoter, four truncated mutations were generated. The transcription factor binding site prediction (TFBS)-JASPAR database (http://jaspar.genereg.net/), TRANSFAC ${ }^{\circledR}$, and MatInspector ${ }^{\circledR}$ were used to search for potential binding sites with PPAR $\alpha \mathrm{b}$, in the Fads6 promoter sequence. According to the manufacturer's 
protocol, truncated mutants were designed and produced with Muta-directTM site-directed mutagenesis kit (SBS Genetech, Shanghai, China) from the deletion mutant pGL3-basic-Fads6-5, which was wild-type. The predicted four binding sites (M1, M2, M3, and M4) were deleted, and the corresponding transcription factor (TF) binding site sequences are shown in Figure 6A. Furthermore, to acquire TF binding site mutations, the method of PCR augmentation referred to a previous study [54]. The influence of TF binding site mutations on promoter activity of ToFads6 were determined by Dual luciferase assay.

\subsection{Cell Culture, Transfection, and Luciferase Assay}

HEK293T cells were cultured in DMEM (Gibco, Grand Island, NY, USA), supplemented with 10\% fetal bovine serum (FBS) (Invitrogen, USA), $100 \mathrm{U} \mathrm{mL}^{-1}$ penicillin, and $100 \mu \mathrm{g} \mathrm{mL}{ }^{-1}$ streptomycin at $37^{\circ} \mathrm{C}$ in a humidified incubator under $5 \% \mathrm{CO}_{2}$. Transfection and dual luciferase reporter assays were described by Li et al. [55]. Relative luciferase activities (firefly and renilla luciferase activities) were measured by the VICTOR ${ }^{\mathrm{TM}}$ X2 Multilabel Plate Reader (PerkinElmer, Inc., Waltham, MA, USA). Moreover, small interfering RNA (siRNA) or plasmids were transfected using Lipofectamine RNAiMAX or Lipofectamine 2000 transfection reagent (Invitrogen, USA) into TOCF cells according to manufacturer's instructions [27,52].

\subsection{Expression Analysis of ToFads6 with ToPPARab}

Construction of ToPPAR $\alpha \mathrm{b}$ recombinant plasmids and siRNA was described as by Zhu et al. [27]. The PPAR $\alpha \mathrm{b}$ siRNA sequence is listed in Table S1. After transfection into TOCF cells, total RNA and protein were isolated at specific time points $(0 \mathrm{~h}, 6 \mathrm{~h}, 12 \mathrm{~h}$, and $24 \mathrm{~h})$, as described above. Additionally, agonists and transcription factor inhibitors were used to investigate the role of transcription factors on the regulation of Fads6 desaturase in T. ovatus. WY-14643 (Sigma-Aldrich) was used as a PPAR $\alpha \mathrm{b}$ agonist, whereas GW6471 (Sigma-Aldrich) was used as a PPAR $\alpha \mathrm{b}$ inhibitor. TOCF cells were seeded in 6-well plates, at a density of $2 \times 10^{6}$ cells per well, in L15 media supplemented with $10 \%$ FBS. Plates were incubated for $24 \mathrm{~h}$, at $28^{\circ} \mathrm{C}$. The cells were washed and incubated for $1 \mathrm{~h}$ in FBS-free L15 medium, prior to incubation with WY-14643 (0.1, 1, and $4 \mu \mathrm{mol} / \mathrm{L})$ or GW6471 $(0.1,1$, and $4 \mu \mathrm{mol} / \mathrm{L})$, in triplicate for $24 \mathrm{~h}$. Cells were lysed in the wells and harvested for RNA extraction after $24 \mathrm{~h}$.

\subsection{Electrophoretic Mobility Shift Assay (EMSA)}

EMSA was carried out as previously described [56]. In brief, the lysates of HEK293T cells, transfected with pcDNA3.1-Flag-PPAR $\alpha \mathrm{b}$ were prepared for DNA/protein conjugation reactions. The EMSA Probe Biotin Labeling Kit (Beyotime, Shanghai, China) was used to label mutated and wild-type oligonucleotides (Table S1) for EMSA biotin-labeled probes, according to the manufacturer's instructions. DNA/protein binding reactions were performed using an EMSA/Gel-Shift Kit (Beyotime, China) at $25{ }^{\circ} \mathrm{C}$, based on the manufacturer's instructions. To detect the specificity of DNA/protein binding reactions, competition assays were carried out with $100 \times$ excessive unlabeled wild-type or mutated probes. Completed reactions were separated on nondenaturing $4 \%$ PAGE gels for $20 \mathrm{~min}$. The proteins were developed by autoradiography using a LightShift ${ }^{\circledR}$ Chemiluminescent EMSA Kit (Pierce, USA).

\subsection{Statistical Analysis}

All experiments were carried out in triplicate. All values were expressed as the mean $\pm \operatorname{SD}(n=3)$. Significant differences were analyzed using one way analysis of variance tests. $p<0.05$ was considered statistically significant. 
Supplementary Materials: Supplementary materials can be found at http:/ / www.mdpi.com/1422-0067/20/1/ 23/s1.

Author Contributions: K.-C.Z., S.-G.J., and D.-C.Z. designed the research and wrote the paper. S.L. and K.-C.Z. performed the research. H.-Y.G. and N.Z. analyzed the data. B.-S.L. and L.G. contributed reagents/materials/analysis tools.

Acknowledgments: The study was supported by the China Agriculture Research System (CARS-47), the Central Public-interest Scientific Institution Basal Research Fund, the Chinese Academy of Fishery Sciences (2016HY-JC0304), the Fishing Port Construction and Fishery Development Special Funds for Guangdong Province (Sci-tech Popularization, 2017A0008), and the National Infrastructure of Fishery Germplasm Resources Project (2018DKA30407).

Conflicts of Interest: The authors declare no conflicts of interest.

\section{Abbreviations:}

$\begin{array}{ll}\text { Fads } & \text { Fatty acid desaturases } \\ \text { EMSA } & \text { Electrophoretic mobile shift assays } \\ \text { LC-PUFA } & \text { Long-chain polyunsaturated fatty acids } \\ \text { PPAR } \alpha \mathrm{b} & \text { Transcription factor peroxisome proliferator-activated receptor alpha b } \\ \text { Elovl } & \text { Elongation of very long-chain fatty acids } \\ \text { HNF4 } & \text { Hepatocyte nuclear factor-4 } \\ \text { NR1H3 } & \text { Nuclear receptor subfamily } 1 \text { group H member } 3 \\ \text { SREBP } & \text { Sterol-regulatory element binding protein } \\ \text { NF-kB } & \text { Nuclear factor-kappa B } \\ \text { PPREs } & \text { PPAR response elements } \\ \text { FAMEs } & \text { Fatty acid methyl esters } \\ \text { TLC } & \text { Thin-layer chromatography } \\ \text { TOCF } & \text { T. ovatus caudal fin }\end{array}$

\section{References}

1. Castro, C.L.F.; Tocher, D.R.; Monroig, Ó. Long-chain polyunsaturated fatty acid biosynthesis in chordates: Insights into the evolution of Fads and Elovl gene repertoire. Prog. Lipid Res. 2016, 62, 25-40. [CrossRef]

2. Park, W.J.; Kothapalli, K.S.; Lawrence, P.; Tyburczy, C.; Brenna, J.T. An alternate pathway to long-chain polyunsaturates: The FADS2 gene product Delta8-desaturates 20:2n-6 and 20:3n-3. J. Lipid Res. 2009, 50, 1195-1202. [CrossRef] [PubMed]

3. Tocher, D.R. Fatty acid requirements in ontogeny of marine and freshwater fish. Aquac. Res. 2010, 41, 717-732. [CrossRef]

4. Monroig, Ó.; Li, Y.Y.; Tocher, D.R. Delta-8 desaturation activity varies among fatty acyl desaturases of teleost fish: High activity in delta-6 desaturases of marine species. Comp. Biochem. Physiol. B 2011, 159, $206-213$. [CrossRef] [PubMed]

5. Vagner, M.; Santigosa, E. Characterization and modulation of gene expression and enzymatic activity of delta-6 desaturase in teleosts: A review. Aquaculture 2011, 315, 131-143. [CrossRef]

6. Miyazaki, M.; Ntambi, J.M. Fatty acid desaturation and chain elongation in mammals. In Biochemistry of Lipids, Lipoproteins and Membranes, 5th ed.; Vance, D.E., Vance, J.E., Eds.; Elsevier: Amsterdam, The Netherlands, 2008; pp. 191-212.

7. Gregory, M.K.; See, V.H.L.; Gibson, R.A.; Schuller, K.A. Cloning and functional characterization of a fatty acyl elongase from southern bluefin tuna (Thunnus maccoyii). Comp. Biochem. Physiol. B 2010, 155, 178-185. [CrossRef]

8. Li, Y.Y.; Monroig, Ó.; Zhang, L.; Wang, S.Q.; Zheng, X. Vertebrate fatty acyl desaturase with D4 activity. Proc. Natl. Acad. Sci. USA 2010, 107, 16840-16845. [CrossRef]

9. Morais, S.; Mourente, G.; Ortega, A.; Tocher, J.A.; Tocher, D.R. Expression of fatty acyl desaturase and elongase genes, and evolution of DHA: EPA ratio during development of unfed larvae of Atlantic bluefin tuna (Thunnus thynnus L.). Aquaculture 2011, 313, 129-139. [CrossRef] 
10. Wang, S.Q.; Monroig, Ó.; Tang, G.X.; Zhang, L.; You, C.H.; Tocher, D.R.; Li, Y.Y. Investigating long-chain polyunsaturated fatty acid biosynthesis in teleost fish: Functional characterization of fatty acyl desaturase (Fads2) and Elovl5 elongase in the catadromous species, Japanese eel Anguilla japonica. Aquaculture 2014, 434, 57-65. [CrossRef]

11. Xie, D.Z.; Chen, F.; Lin, S.Y.; Wang, S.Q.; You, C.H.; Monroig, Ó.; Tocher, D.R.; Li, Y.Y. Cloning, functional characterization and nutritional regulation of $\Delta 6$ fatty acyl desaturase in the herbivorous euryhaline teleost Scatophagus argus. PLoS ONE 2014, 9, e90200. [CrossRef]

12. Ngoh, S.Y.; Tan, D.; Shen, X.; Kathiresan, P.; Jiang, J.; Liew, W.C.; Thevasagayam, N.M.; Kwan, H.Y.; Saju, J.M.; Prakki, S.R.; et al. Nutrigenomic and nutritional analyses reveal the effects of pelleted feeds on Asian seabass (Lates calcarifer). PLoS ONE 2015, 10, e0145456. [CrossRef] [PubMed]

13. Ota, T.; Suzuki, Y.; Nishikawa, T.; Otsuki, T.; Sugiyama, T.; Irie, R.; Wakamatsu, A.; Hayashi, K.; Sato, H.; Nagai, K.; et al. Complete sequencing and characterization of 21,243 full-length human cDNAs. Nat. Genet. 2004, 36, 40-45. [CrossRef] [PubMed]

14. Wang, J.; Huo, K.; Ma, L.; Tang, L.; Li, D.; Huang, X.; Yuan, Y.; Li, C.; Wang, W.; Guan, W.; et al. Toward an understanding of the protein interaction network of the human liver. Mol. Syst. Biol. 2011, 7, 536. [CrossRef] [PubMed]

15. Giancaspero, T.A.; Galluccio, M.; Miccolis, A.; Leone, P.; Eberini, I.; Iametti, S.; Indiveri, C.; Barile, M. Human FAD synthase is a bi-functional enzyme with a FAD hydrolase activity in the molybdopterin binding domain. Biochem. Biophys. Res. Commun. 2015, 465, 443-449. [CrossRef] [PubMed]

16. Kota, B.P.; Huang, T.H.; Roufogalis, B.D. An overview on biological mechanisms of PPARs. Pharmacol. Res. 2005, 51, 85-94. [CrossRef] [PubMed]

17. Sampath, H.; Ntambi, J.M. Polyunsaturated fatty acid regulation of genes of lipid metabolism. Annu. Rev. Nutr. 2005, 25, 317-340. [CrossRef] [PubMed]

18. Chakravarthy, M.V.; Lodhi, I.J.; Yin, L.; Malapaka, R.R.V.; Xu, H.E.; Turk, J.; Semenkovich, C. Identification of a physiologically relevant endogenous ligand for PPARalpha in liver. Cell 2009, 138, 476-488. [CrossRef]

19. Lefebvre, P.; Chinetti, G.; Fruchart, J.C.; Staels, B. Sorting out the roles of PPARa in energy metabolism and vascular homeostasis. J. Clin. Investig. 2006, 116, 571-580. [CrossRef]

20. Tang, C.R.; Cho, H.P.; Nakamura, M.T.; Clarke, S.D. Regulation of human Delta-6 desaturase gene transcription: Identification of a functional direct repeat-1 element. J. Lipid Res. 2003, 44, 686-695. [CrossRef]

21. Dong, X.J.; Tan, P.; Cai, Z.N.; Xu, H.L.; Li, J.Q.; Ren, W.; Xu, H.G.; Zuo, R.T.; Zhou, J.F.; Mai, K.S. Regulation of FADS2 transcription by SREBP-1 and PPAR- $\alpha$ influences LC-PUFA biosynthesis in fish. Sci. Rep. 2017, 7, 40024. [CrossRef]

22. Navidshad, B.; Royan, M. Peroxisome Proliferator-Activated Receptor Alpha (PPAR alpha), a key regulator of lipid metabolism in avians. Crit. Rev. Eukaryot. Gene Expr. 2016, 26, 303-308. [CrossRef]

23. Dong, Y.W.; Zhao, J.H.; Chen, J.L.; Wang, S.Q.; Liu, Y.; Zhang, Q.H.; You, C.H.; Monroig, O.; Tocher, D.R.; Li, Y.Y. Cloning and characterization of $\Delta 6 / \Delta 5$ fatty acyl desaturase (Fad) gene promoter in the marine teleost Siganus canaliculatus. Gene 2018, 647, 174-180. [CrossRef] [PubMed]

24. Sun, L.Y.; Guo, H.Y.; Zhu, C.Y.; Ma, Z.H.; Jiang, S.G.; Zhang, D.C. Genetic polymorphism of breeding populations of golden pompano (Trachinotus ovatus). South China Fish. Sci. 2014, 10, 67-71.

25. Zhen, P.L.; Ma, Z.H.; Guo, H.Y.; Jiang, S.G.; Zhang, D.C. Ontogenetic development of caudal skeletons in Trachinotus ovatus larvae. South China Fish. Sci. 2014, 10, 45-50.

26. Sun, X.X.; Guo, H.Y.; Zhu, K.C.; Zhang, N.; Yu, W.B.; Wu, N.; Jiang, S.G.; Zhang, D.C. Feed type regulates the fatty acid profiles of golden pompano Trachinotus ovatus (Linnaeus 1758). J Appl. Anim. Res. 2018, 46, 60-63. [CrossRef]

27. Zhu, K.C.; Song, L.; Zhao, C.P.; Guo, H.Y.; Zhang, N.; Guo, L.; Liu, B.S.; Jiang, S.G.; Zhang, D.C. The Transcriptional factor PPAR $\alpha \mathrm{b}$ positively regulates Elovl5 elongase in golden pompano Trachinotus ovatus (Linnaeus 1758). Front. Physiol. 2018, 9, 1340. [CrossRef]

28. Shanklin, J.; Whittle, E.; Fox, B.G. Eight histidine residues are catalytically essential in a membrane-associated iron enzyme, stearoyl-CoA desaturase, and are conserved in alkane hydroxylase and xylene monooxygenase. Biochemistry 1994, 33, 12787-12794. [CrossRef]

29. Geay, F.; Tinti, E.; Mellery, J.; Michaux, C.; Larondelle, Y.; Perpète, E.; Kestemont, P. Cloning and functional characterization of $\Delta 6$ fatty acid desaturase (FADS2) in Eurasian perch (Perca fluviatilis). Comp. Biochem. Physiol. B 2016, 191, 112-125. [CrossRef] 
30. Zuo, R.T.; Mai, K.S.; Xu, W.; Dong, X.J.; Ai, Q.H. Molecular cloning, tissue distribution and nutritional regulation of a $\Delta 6$-fatty acyl desaturase-like enzyme in large yellow croaker (Larimichthys crocea). Aquac. Res. 2016, 47, 445-459. [CrossRef]

31. Huang, Y.S.; Lin, Z.D.; Rong, H.; Hao, M.L.; Zou, W.G.; Li, S.K.; Wen, X.B. Cloning, tissue distribution, functional characterization and nutritional regulation of $\Delta 6$ fatty acyl desaturase in chu's croaker Nibea coibor. Aquaculture 2017, 479, 208-216. [CrossRef]

32. Xu, G.X.; Guo, C.C.; Shan, H.Y.; Kong, H.Z. Divergence of duplicate genes in exon-intron structure. Proc. Natl. Acad. Sci. USA 2012, 109, 1187-1192. [CrossRef] [PubMed]

33. Kuah, M.K.; Jaya-Ram, A.; Shu-Chien, A.C. The capacity for long-chain polyunsaturated fatty acid synthesis in a carnivorous vertebrate: Functional characterisation and nutritional regulation of a Fads2 fatty acyl desaturase with Delta 4 activity and an Elovl5 elongase in striped snakehead (Channa striata). Biochim. Biophys. Acta BBA Mol. Cell Biol. Lipids 2014, 1851, 248-260.

34. Morais, S.; Castanheira, F.; Martinez-Rubio, L.; Conceicao, L.E.C.; Tocher, D.R. Long chain polyunsaturated fatty acid synthesis in a marine vertebrate: Ontogenetic and nutritional regulation of a fatty acyl desaturase with Delta 4 activity. Biochim. Biophys. Acta BBA Mol. Cell Biol. Lipids 2012, 1821, 660-671. [CrossRef] [PubMed]

35. Oboh, A.; Kabeya, N.; Carmona-Antonanzas, G.; Castro, L.F.C.; Dick, J.R.; Tocher, D.R.; Monroig, O. Two alternative pathways for docosahexaenoic acid (DHA, 22:6n-3) biosynthesis are widespread among teleost fish. Sci. Rep. 2017, 7, 3889. [CrossRef] [PubMed]

36. Li, S.L.; Mai, K.S.; Xu, W.; Yuan, Y.H.; Zhang, Y.J.; Ai, Q.H. Characterization, mRNA expression and regulation of Delta 6 fatty acyl desaturase (Fads2) by dietary n-3 long chain polyunsaturated fatty acid (LC-PUFA) levels in grouper larvae (Epinephelus coioides). Aquaculture 2014, 434, 212-219. [CrossRef]

37. Lopes-Marques, M.; Ozorio, R.; Amaral, R.; Tocher, D.R.; Monroig, O.; Castro, L.F.C. Molecular and functional characterization of a fads 2 orthologue in the Amazonian teleost, Arapaima gigas. Comp. Biochem. Physiol. B 2017, 203, 84-91. [CrossRef] [PubMed]

38. Tanomman, S.; Ketudat-Cairns, M.; Jangprai, A.; Boonanuntanasarn, S. Characterization of fatty acid delta-6 desaturase gene in Nile tilapia and heterogenous expression in Saccharomyces cerevisiae. Comp. Biochem. Physiol. B 2013, 166, 148-156. [CrossRef]

39. Bell, J.G.; McEvoy, J.; Tocher, D.R.; McGhee, F.; Campbell, P.J.; Sargent, J.R. Replacement of fish oil with rapeseed oil in diets of Atlantic salmon (Salmo salar) affects tissue lipid compositions and hepatocyte fatty acid metabolism. J. Nutr. 2001, 131, 1535-1543. [CrossRef]

40. O'Malley, B.W.; Towle, H.C.; Schwartz, R.J. Regulation of gene expression in eucaryotes. Annu. Rev. Genet. 1977, 11, 239-275. [CrossRef]

41. Zhu, K.C.; Chen, L.P.; Zhao, J.K.; Wang, H.J.; Wang, W.M.; Li, Z.; Wang, H.L. Molecular characterization and expression patterns of myogenin in compensatory growth of Megalobrama amblycephala. Comp. Biochem. Physiol. B 2014, 170, 10-17. [CrossRef]

42. Larkin, M.A.; Blackshields, G.; Brown, N.P.; Higgins, D.G. ClustalW and ClustalX version 2. Bioinformatics 2007, 23, 2947-2948. [CrossRef]

43. Tamura, K.; Stecher, G.; Peterson, D.; Filipski, A.; Kumar, S. MEGA6: Molecular Evolutionary Genetics Analysis version 6.0. Mol. Biol. 2013, 3, 2725-2729. [CrossRef]

44. Agaba, M.K.; Tocher, D.R.; Zheng, X.Z.; Dickson, C.A.; Dick, J.R.; Teale, A.J. Cloning and functional characterisation of polyunsaturated fatty acid elongases from marine and freshwater teleost fish. Comp. Biochem. Physiol. B 2005, 142, 342-352. [CrossRef] [PubMed]

45. Li, M.; Mai, K.S.; He, G.; Ai, Q.H.; Zhang, W.B.; Xu, W.; Wang, J.; Liufu, Z.G.; Zhang, Y.J.; Zhou, H.H. Characterization of two $\Delta 5$ fatty acyl desaturases in abalone (Haliotis discus hannai Ino). Aquaculture 2013, 416, 48-56. [CrossRef]

46. Hastings, N.; Agaba, M.K.; Tocher, D.R.; Leaver, M.J.; Dick, J.R.; Sargent, J.R.; Teale, A.J. A vertebrate fatty acid desaturase with $\Delta 5$ and $\Delta 6$ activities. Proc. Natl. Acad. Sci. USA 2001, 98, 14304-14309. [CrossRef] [PubMed]

47. Zhu, K.C.; Yu, W.B.; Guo, H.Y.; Zhang, N.; Guo, L.; Liu, B.S.; Jiang, S.G.; Zhang, D.C. Genomic structure, expression pattern and polymorphisms of GILT in golden pompano Trachinotus ovatus (Linnaeus 1758). Gene 2018, 665, 18-25. [CrossRef] [PubMed] 
48. Livak, K.J.; Schmittgen, T.D. Analysis of relative gene expression data using real-time quantitative PCR and the $2^{-\triangle \Delta C T}$ method. Methods 2001, 25, 402-408. [CrossRef] [PubMed]

49. Chen, N.; Wan, X.L.; Huang, C.X.; Wang, W.M.; Liu, H.; Wang, H.L. Study on the immune response to recombinant Hsp70 protein from Megalobrama amblycephala. Immunobiology 2014, 219, 850-858. [CrossRef]

50. Sambrook, J.; Fritsch, E.F.; Maniatis, T. Molecular Cloning; Cold Spring Harbor Laboratory Press: New York, NY, USA, 1989; Volume 2.

51. Wei, S.N.; Yu, W.P.; Qin, Q.W. Establishment of a new fish cell line from the caudal fin of golden pompano Trachinotus ovatus and its susceptibility to iridovirus. J. Fish. Biol. 2018, 92, 1675-1686. [CrossRef]

52. Ding, Y.; Ao, J.Q.; Huang, X.H.; Chen, X.H. Identification of two subgroups of type I IFNs in perciforme fish large yellow croaker Larimichthys crocea provides novel insights into function and regulation of fish type I IFNs. Front. Immunol. 2016, 7, 343. [CrossRef]

53. Sun, L.Y.; Zhang, D.C.; Jiang, S.G.; Guo, H.Y.; Zhu, C.Y. Isolation and characterization of 21 polymorphic microstatellites in golden pompano Trachinotus ovatus. Conserv. Genet. Resour. 2013, 5, 1107-1109. [CrossRef]

54. Dong, Y.; Wang, S.Q.; Chen, J.L.; Zhang, Q.H.; Liu, Y.; You, C.H.; Monroig, O.; Tocher, D.R.; Li, Y.Y. Hepatocyte Nuclear factor $4 \alpha(\mathrm{HNF} 4 \alpha)$ is a transcription factor of vertebrate fatty acyl desaturase gene as identified in marine teleost Siganus canaliculatus. PLoS ONE 2016, 11, e0160361. [CrossRef] [PubMed]

55. Li, S.L.; Monroig, O.; Wang, T.J.; Yuan, Y.H.; Navarro, J.C.; Hontoria, F.; Liao, K.; Tocher, D.R.; Mai, K.S.; Xu, W. Functional characterization and differential nutritional regulation of putative Elovl5 and Elovl4 elongases in large yellow croaker (Larimichthys crocea). Sci. Rep. 2017, 7, 2303. [CrossRef] [PubMed]

56. Yu, S.; Mu, Y.; Ao, J.; Chen, X. Peroxiredoxin IV regulates pro-inflammatory responses in large yellow croaker (Pseudosciaena crocea) and protects against bacterial challenge. J. Proteome Res. 2010, 9, 1424-1436. [CrossRef]

(C) 2018 by the authors. Licensee MDPI, Basel, Switzerland. This article is an open access article distributed under the terms and conditions of the Creative Commons Attribution (CC BY) license (http:// creativecommons.org/licenses/by/4.0/). 